\title{
Cultural, Maternal and Environmental Factors Contributing to High Under-Five Mortality in Identified Hotspots in Nigeria
}

\author{
Oluwabukola O. Adesuyi, Urbanus M. Kioko, and Martine O. Oleche
}

\begin{abstract}
Under-five mortality rate in Nigeria is among the world's highest with northern Nigeria having the most appalling under-five health indicators. Despite the streams of studies, research on Nigeria, there is still a gap on the cultural, maternal, and environmental factors contributing to the high under-five mortality in the identified hotspots in Nigeria. The study utilized data from the 2013 Nigeria Demographic Health Survey (NDHS) reports. Results revealed that Spatial dependence across the study area was confirmed with Moran's I testing positive (0.4689 and a $P$-value of 0.01 ), an indication of the presence of auto correlation. Six states namely Zamfara, Bauchi, Jigawa, Sokoto, Kebbi and Katsina, were identified as having the highest under-five mortality rates ranging from 162-221 deaths per 1000 live births from the spatial analysis. The variables identified as contributing to the high under-five mortalities in these states were maternal education, Age of the mother, religion, wealth index, antenatal visits, hospital delivery, post natal visit, age at first birth, Partner's education, distance to the nearest health care facility and Sanitation (flush toilet), and piped water. However, the variable Age of the mother and, Age at first birth were relatively significant and consistent across the six states under examination. The six states were also observed to be part of the poorest states in the country. Therefore, Poverty and child marriage was observed to be common in the six states, hence the likely clustering pattern observed and positive autocorrelation. Awareness through the media and all available means need to be intensified on the practice of child marriages, while emphasis needs to be laid on effective programs, policies and amendments of laws especially the laws that affects children's marriages and child rights, while unvarying age should be set for a child to marry in order to protect the rights of children in the country, to help eradicate/reduce the under-five mortality rate. Programs that will help alleviate poverty in these regions should also be of uttermost priority to stabilize the families financially, improve living standards, provide better health care, eradicate/ reduce child marriages/under-aged mothers who eventually will reduce under-five mortality in these regions.
\end{abstract}

Key words - Cultural, Environmental and Maternal Factors; Under-five mortality hotspots; Underage marriage.

\section{INTRODUCTION}

The use of geographic information systems to support public health systems is already spreading across the world. The importance of spatial assessment and map view to health analysis and planning cannot be over emphasized. Maps provide better information about health phenomenon and presents to health officers' alternatives through which proper intervention activities can be carried out [1]. Autocorrelation

Published on September 07, 2021.

* Oluwabukola O. Adesuyi

(corresponding e-mail: buksib@yahoo.com)

School of Economics, University of Nairobi, Kenya. is one of the ways to achieve this. Tobler [2] captured the essence of spatial autocorrelation as everything is related to everything else, but near things are more related than distant things. In other words, spatial autocorrelation means attribute values (say mortality) of proximal entities (say metropolitan areas) will likely be more clustered or share similar values than distant ones. For example, if there is water pollution, it is expected that the pollution levels would be more similar between Lagos and Abeokuta (a nearby city), than between Lagos an Ile-Ife (a faraway city). This may be as a result of similarities in the underlying social and economic processes that cause pollution or water processes that retain pollutants over large distances and disperse pollutants from region to region. Autocorrelation tests use point, line, or area features that have attribute values attached to them. Therefore, when health officers view the location of the health incidents, facilities and infrastructure that are located around it and the location of the households that are affected, then more insights can be gained into the magnitude of the effect of the occurrences. However, studies on spatial analysis of underfive mortality clustering, maternal and environmental factors contributing to it are limited in resource constrained countries. This limits opportunities for deploying effective and appropriate health interventions.

Without any doubt, the world made remarkable progress in child survival in the past few decades. Millions of children have better survival chances than in 1990 where 1 in 26 children died before reaching age 5 in 2017, compared to 1 in 11 in 1990 [3]. Moreover, global progress in reducing child mortality has been accelerated in the 2000-2017 period compared with the 1990s. The annual rate of reduction in the global under-five mortality rate increased from 1.9 per cent in 1990-2000 to 4.0 per cent in 2000-2017. However, despite the global progress in reducing child mortality over the past few decades, an estimated 5.4 million children under age 5 died in 2017 - approximately half of these deaths occurred in sub-Saharan Africa. There is a wide variation between the developed and the developing countries in terms of their contribution to the global under-five mortality burden, but the situation is worse for the sub-Saharan African countries. Some of the contributing factors are the poor or inadequate health facilities, care, and may be linked to cultural, political and environmental factors [4].

Under-five mortality rate in Nigeria is among the world's highest with northern Nigeria having the most appalling

*Urbanus M. Kioko,

School of Economics, University of Nairobi, Kenya.

*Martine O. Oleche,

School of Economics, University of Nairobi, Kenya. 
under-five health indicators. Despite the streams of studies, research, and knowledge on determinants of under-five mortality in Nigeria such as [5]-[7], there is still a gap in knowledge, especially in under-five mortality clustering and factors contributing to the clustering. Under-five mortality clustering refers to the variability in the spread of under-five mortality in a population. It explores why under-five mortality is clustered within certain individuals, families, or communities. Universally, child deaths are unevenly distributed among women [8]. Child deaths tend to concentrate in some families or regions and among few women with certain characteristics. This study will check if the clustering observed is auto correlated, and will check cultural, maternal and environmental factors contributing to it. This aspect of under-five mortality study is relatively new in Nigeria and this study will contribute to it.

\section{Aim AND OBJEctives OF THE STUdy}

1. To determine if the under-five mortality is spatially autocorelated or it occurs independently in Nigeria

2. To explore association of cultural, environmental, and maternal factors on the identified hotspots for under-five mortality in Nigeria.

3. To recommend policy implications based on research findings.

\section{EMPIRICAL REVIEW}

Burke et al. [9] carried out a study on "Causes of disparity in under-5 mortality across sub-Saharan Africa. The study objective was to analyze the spatial factors associated with variation in mortality across countries in Sub Saharan Africa. Findings showed that differences in U5MR accounted for 74 $78 \%$ of overall variation in under- 5 mortality across space and over time within-country, while mortality across countries and borders was cross $8-15 \%$, indicating that factors within a country were the main drivers of the observed mortality patterns. They noted that if children continued to live in the high mortality areas, the countries will not be able to meet SDG mortality targets.

Salau [10] investigated district level variations in U5MR in South Africa, using exploratory Spatial Data Analysis techniques (Moran's I and LISA). The result showed that U5MR appeared to cluster in sections of some provinces. The result of Moran's I showed statistically significant Spatial Autocorrelation (SAC) in U5MR (Moran's I $=0.5185$, $\mathrm{p}<0.0001)$. The richer provinces of Gauteng and Western Cape had low U5MR surrounded by areas of equally low mortality. In summary, the results showed clustering of U5MR at the district level.

Uthman [11] carried out a study to examine the impact of state-level access to basic environmental services and neighborhood deprivation of U5MR in Nigeria. The study used exploratory spatial data analyses to determine the statelevel association between environmental, neighborhood deprivation and U5MR. The results showed that spatial distribution of U5MR was non-random and clustered with a Moran's $I=0.654(p=0.001)$. Spatial clustering suggested that North-east and North-west can be grouped as U5MR "hot-spot" (these are areas with the highest level of U5MR), while Southwest, South-south, and South-east were grouped under U5MR "cold-spot" (that is, areas with the lowest level of U5MR).

Factors that have been established to contribute to underfive mortality are in the study Quattrochi et al. [12] in their study on Gambia established that risks of under-5 mortality were associated with mother's ethnicity and household wealth. Maternal education, women age at first birth, women current age, childbirth order, preceding birth interval, birth type, and occupation of mother were significant predictors of under-five mortality [13]. Singh and Tripath [14] showed that maternal education, wealth index and breastfeeding were protective factors across all birth orders. Mesike and Mojekwu [15] on the other hand concluded that immunization, low polluting fuel and household dwelling infrastructure such as method of solid waste disposal, refuse disposal facility, roofing and flooring material used, as well as income contributed most to predicting mortality rate. Alaba et al. [16] found the highest incidence of U5MR in Nigeria resulted from unprotected water, unavailability or use of unprotected toilet facility, High illiteracy level, the type of cooking fuel, the poorest wealth index quintile, the rural place of residence, and the use of inappropriate place of delivery were found and concentrated among several states from the North East, West and Central Zones of Nigeria. Another study was done on Zamfara state in Nigeria and it identified meager admittance to health care centers, poor hygiene and living situations which are characteristic of rural and deprived Nigerian northern sceneries as variables contributing to U5M in Zamfara.

This study is different from the works done above especially Alaba et al. [16] as a newer data was used while employing different econometric techniques and the focus was on the areas with the highest under-five mortality in the country. Also, this study introduced some cultural variables, as opposed to only maternal and environmental variables carried out by [16]. This study intends to explore the contributing child marriage variables, while controlling for environmental and other maternal variables contributing to the high under-five mortality in these hotspot regions, using a more recent data and econometric techniques.

\section{CONCEPTUAL FramewOrK}

The theoretical framework used in this study is based on the model of five groups of health determinants theory formulated by Mosley and Chen [17]. This illustrates the effect of proximate determinants on the survival of children in developing countries. The proximate determinants are categorized into five groups: maternal factors; environmental contamination; nutrient deficiency; injuries; and personal illness control (prevention, treatment).

The survival of a child is linked to several social and biological factors surrounding it especially the mother's cultural, maternal, and environmental factors amidst others. The uniqueness of this model is the use of proximate determinants approach to the study of child survival, and this is based on a number of principles. When children are born, they are expected to survive (about 97\%), however, this is mostly not the case because of the biological, economic, environmental, and social factors. These factors operate 
through more specific determinants, that in turn influence the survival of a child.

The model therefore identified these key proximate determinants in which all economic and social must function through, and categorized them into five groups as:

Maternal factors which are the factors surrounding the health of the mother, which in turn have an impact on the pregnancy outcome and the survival of the newborn. These factors could be the young age of the mother (underage), the spacing of births which are short, amongst others.

Environmental contamination refers to the transmitters of infections in the environment which could include water, air, food, skin amongst others. These are the means whereby infectious diseases can be transmitted to the mother and child, which could viral and parasitic diseases, respiratory and intestinal diseases, skin infections and other diseases which lead to sicknesses of the mother and infant.

Nutrient Deficiency is about the nutritional intake of both the mother and the infant. Proper nutrition should start with the mother right from the pregnancy or gestation period, because the mother's nutritional intake has effect on the fetus's health and birth weight. After the baby is born, the nutritional intake of the mother will affect the milk production and lactation for the proper growth and development of the baby, and for the health restoration of the mother. If the case is reversed when it comes to the proper nutrition of the mother and the child, diseases and sicknesses could set in or ultimately death.

Injury such as burns, poisoning and physical injury mostly cannot be predicted. Injuries are mostly random occurrences; however, there are some instances where it can be intentional such as an extreme case of infanticide. The types of Injuries and their frequency in occurrences on the mother or infant depend on the environment and socioeconomic status.

Personal illness deals with prevention and treatment illnesses. A hale and hearty person takes necessary measures in avoiding diseases such as vaccinations, prophylaxis, and traditional ways. However, even after taking necessary measures to avoid illnesses and they still set in, the person takes necessary steps to receive medical treatments, and other steps needed to remedy the illness.

These five groups of proximate determinants operate on the health dynamics of a population. The framework depicts how these five categories of proximate determinants influence the rate of shift of healthy individuals toward sickness: influence both the rate of illness (through prevention) and the rate of recovery (through treatment). Specific states of sickness (infection or nutrient deficiency) are basically transitory: ultimately there is either complete recovery or irreversible consequences manifested by increasing degrees of permanent growth faltering (or other disability among the survivors) and/or death.

\section{THEORETICAL MODEL}

The study used two theories: the Moran's I to measure spacial distribution of under-five mortality, and the theoretical framework from Mosley and Chen [17], and Rosenzweing and Schultz [18], which are based on the interactions between the determinants of health and different types of health inputs and possible health outcomes.

\section{A. Theory 1: Measure of Spatial Distribution-Moran's I}

This global measure of spatial dependence was developed by Moran in 1948 [19]. The index measures spatial dependence based on feature locations and attribute values. The measure evaluates whether the pattern is clustered, dispersed, or random.

Therefore, the null hypothesis (Ho) states that there is no spatial autocorrelation (dependence) across the study area (random), in this case across Nigeria. When the z-score or pvalue indicates statistical significance, a positive Moran's I index value indicates tendency towards clustering while a negative Moran's I index value indicates tendency toward dispersion.

Moran's I is expressed as:

$I=\frac{N}{W} \frac{\sum_{i} \sum_{j} w_{i j}\left(x_{i}-\bar{x}\right)\left(x_{j}-\bar{x}\right)}{\sum_{i}\left(x_{i}-\bar{x}\right)^{2}}$

where:

$\mathrm{X}=$ variable of interest;

$\mathrm{N}=$ number of spatial units indexed by $\mathrm{i}$ and $\mathrm{j}$;

$\bar{x}=$ the mean of $\mathrm{x}$;

$w_{i j}=$ is a matrix of spatial weights with zeros on the diagonal

(i.e., $w_{i i}=0$ );

$\mathrm{W}=$ sum of all $w_{i j}$.

Values of I range from -1 to +1 . When the values of I are significantly below $-1 /(\mathrm{N}-1)$, it indicates a negative spatial autocorrelation. Similarly, when the values of I are significantly above $-1 /(\mathrm{N}-1)$, it signifies a positive spatial autocorrelation.

\section{B. Theory 2: Mosley and Chen [17], and Rosenzweing and} Schultz [18] Framework

These frameworks guide in the understanding of variables connected and linked with child survival or under-five mortality. They also guide in the selection of independent based on the assumption that proximate determinants (economic, demographic, and medical mechanism) affect the probability of child survival through a set of biological mechanisms. Following Rosenzweing and Schultz [18], we assume that households maximize utility given a utility function as:

$U=(X, Y, H)$

where $\mathrm{U}$ is the utility function, $\mathrm{X}$ is a set of alternatives of goods and services that have no direct effect on health, Y signifies the consumption of goods and services that give direct utility and directly affect the health of an individual, and $\mathrm{H}$, the health status of an individual. Therefore:

$\mathrm{U}=\mathrm{U}(\mathrm{H}, \mathrm{Xa}, \mathrm{Yb}), \mathrm{a}=1 \ldots, \mathrm{n} ; \mathrm{b}=\mathrm{n}+1, \ldots, \mathrm{m} .(1)$

where $H$ is the child health, $X a=n$ goods that do not affect child health (for example, clothing), and $Y b=\mathrm{m}-\mathrm{n}$ goods that affect child health (e.g., food). However, child's health is influenced by exogenous variables and household chooses these variables in such a manner that it will maximize the health outcome of a child (survival or mortality). The variables depend on the child health endowment $(\mu)$, household preferences, market prices and household physical 
environmental constraints and household wealth. All these characteristics are assumed to be exogenous to the household decisions about behaviors and investment related to child health. According to Schultz [18], the production function is given as:

$$
H=h(Y, C, \mu)
$$

where $\mathrm{H}$ is the child health, $Y$ represents proximate maternal and environmental inputs to child health such as maternal education, residence, sanitation, birth order; $Z$ represents the health input of a child such as preventive and curative health care; $C$ represents other inputs, and $\mu$ refers to the child's unobserved health endowment. Household therefore maximizes utility equation 1 , given the production function equation 3, subject to household's budget constraint expressed as:

$I=P x+P y+P z+P c$

where $I$ is the total household income, $P x$ represents the price per unit of $\mathrm{X}, P y$ represents the price per unit of $Y, P Z$ represents the price per unit of $Z$ and $P c$ represents the price per unit of $Z$. Solving the household's maximization model in equations (3)-(5), yield the following reduced-form of input demand equations:

$$
\begin{aligned}
& X=X\left(P_{x}, P_{y}, P_{z}, P_{c}, I, \mu\right) \\
& Y=Y\left(P_{x}, P_{y}, P_{z}, P_{c}, I, \mu\right) \\
& Z=Z\left(P_{x}, P_{y}, P_{z}, P_{c}, I, \mu\right) \\
& C=C\left(P_{x}, P_{y}, P_{z}, P_{c}, I, \mu\right)
\end{aligned}
$$

Using the technique of total differentiation, and following Mwabu [20], the price effects of child health and survival depend on the effects of changes in prices on the demand for health production inputs as well as on the marginal products of these inputs in the production of child health and survival. This in effect means that concurrently, we must estimate the child health production function and input demand parameters, so that the effect of changes in the prices of the various health inputs on child health and survival can be predicted.

Causal effect from inputs to outputs cannot be determined by the estimation of equations 14-17 alone because there is no direct link between them. Therefore, to bridge this disconnect we follow Mwabu [21] who proposed the use of hybrid health production functions. The health outcome (child survival or mortality) $(H)$ is a function of a good $(Y)$ that affects health either directly or indirectly, and $(C)$ is the other variables, prices $\mathrm{P}$, income I and child health endowments $\mu$, in the reduced form, as given in equation:

$H=h\left(Y, P_{x}, P_{z}, P_{c}, I, \mu\right)$

In equation (10), the hybrid equation, $\mathrm{Y}$ is potentially endogenous as it may be affected by the initial health status of the child (8). Caution should be taken however in interpreting the coefficient of $\mathrm{Y}$ as the marginal product of $\mu$ cannot be observe, it therefore creates complications in the interpretation if not controlled for (9). The estimation method should therefore take into account the endogeneity f Y (8). The endogeneity problem in this study was addressed through the use of an instrumented variable (place of residence).

\section{ECONOMETRIC MODEL}

After the Moran's I analysis, the study used the Two stage least square to determine the effects of the cultural, maternal, and environmental variables contributing to the high underfive mortality in the identified hotspot areas.

\section{A. Instrumental Variables Estimation (Two Stage Least Square)}

From the theoretical framework above, the endogeneity of mother's education stems from potential correlation between the error terms $\mu i$ and $\boldsymbol{\epsilon}$ : family background may affect both the mother's education and the child's health; also, the child health endowment might be correlated with observed variables such as mother's health knowledge. The problem in estimating this reduced form equation is that the genetic health endowment is potentially known to the family but is not observed by the researcher. Rosenzweig and Schultz [18] showed that this will lead to biased estimates which would bias OLS estimates. In addition, mother's education may be correlated with unobserved variables (ethnicity, religion, etc.) that, if they directly affect child health, would result in omitted variable bias. Therefore, in order to account for the likely endogeneity of mother's education, this study estimated using the two-stage least square method, using the place of residence as an instrument in order to avoid bias.

\section{B. The Instrument}

The place of residence [22]-[24] of the mother captures regional disparity in education over time. Thus, this instrument captures the appropriate school resource during the mother's school going age which is correlated with mother's schooling and uncorrelated with the child's error term and unobserved variables that could affect child health.

\section{Lorenz Curve and the Gini Coefficient}

The Gini index or Gini coefficient is used as a gauge of economic inequality, measuring income distribution among a population. The Gini coefficient is usually displayed with the use of a graph known as the Lorenz curve. The graph usually has on the $\mathrm{X}$-axis the population, while the Y-axis displays the proportion of the total income of the population. The Lorenz curve denotes inequality in the distribution of either wealth or income. While the Gini coefficient is given as the ratio of the area that lies between the line of equality and the Lorenz curve. The farther away the curve is from the line of equality, represented by the straight diagonal line, the higher the level of inequality. The Gini coefficient is express as a range from 0 (or $0 \%$ ) to 1 (or 100\%).

\section{Principal Component Analysis (PCA)}

To calculate the wealth index variable used for the analysis, the principal component analysis was used. The wealth index was computed using readily available information on a family's ownership (assets) of preferred 
resources like televisions and bicycles; materials used to construct a house; and types of water avenue and sanitation propensity. The index was therefore developed using the principal component analysis (PCA) (10).

Therefore, the asset index for individual $\mathrm{i}$ is defined as:

$A_{i}=\sum_{k}\left[f_{k} \frac{\left(a_{i k}-\bar{a}_{k}\right)}{s_{k}}\right]$

where

$a_{i k}=$ the value of asset $\mathrm{k}$ for household $\mathrm{I}$;

$\bar{a}_{k}=$ the sample mean;

$s_{k}=$ the sample standard deviation.

The PCA therefore uses the goods index then breaks it into wealth groups such as quintiles (poor, middle, rich).

\section{Methodology}

The study made use of two methodologies. For the first part, the under-five mortality (U5M) (death of a child between 0-59 months) for all the 36 states and Federal Capital Territory (FCT) were tabulated. The data counts were then exported into the ArcGIS environment for further analysis. The coefficient of spatial dependence as a result of the spillover effects between the states across the country was calculated using the Moran's I index. The states with the highest and lowest concentration of U5M were identified as the hotspots and cold spots. The Arc GIS was also used to measure the coefficient of spatial dependence/autocorrelation on the identify hotspots and for cluster analysis.

For the second part, the variables were categorized according to their supposed effects on Under-five mortality rate: cultural, maternal, and environmental variables. Therefore, to determine if cultural, maternal, and environmental variables contributed to the high under-five mortality of the states that fall under the hotspots (red zone or red color on the map (Fig. 1.), which are the states with the highest mortality rates) the Two Stage Least Square regression (to control for endogeniety) using cultural, maternal and environmental variables was used for analysis. The Gini coefficient analysis was also used to measure the poverty index for each state under investigation.

\section{A. Data Source}

The study utilized data from the 2013 Nigeria Demographic Health Survey (NDHS) reports [25]. The NDHS is structured to avail data for the populace and health status in Nigeria. The sample for the 2013 NDHS was a national representation which covered the entire population of Nigeria, as well as the population living in noninstitutional areas in the nation.

Nigeria administrative system is divided into states; the states are divided into local governments, and the local governments into localities. From these localities 500 enumeration areas or clusters were gotten, of which the data for analysis was collected. A representative sample of 40,680 families was picked for the research. A stratified three-stage group designs made up of 904 clusters, 532 in rural regions and 372 in urban regions was used in the selecting the representatives. A fixed sample take of 45 households were selected per cluster All females aged 15-49 who were either fixed inhabitants of the families in the 2013 NDHS representative or guests present in the families on the night before the research were entitled to the evaluation. An aggregate of 38,948 females were interrogated out of which 15,545 lived in urban regions and 23,403 in rural regions. 24,529 minors with efficient and imperforate data on date of birth and height (in centimeters) were also collected. The analysis used 119,386 children under the age of five (age in months), and 18,525 under-five children mortality (age in months), also 119,386 female respondents between the ages of $15-49$.

\section{B. Descriptive Statistics of the Study Variables}

The study's dependent variable is the "under-five mortality" with a mean percentage of $15.5 \%$ under-five mortality in the study sample.

The study grouped the independent variables into maternal, cultural, and environmental variables. The Maternal variables are: Maternal education, Age of the mother, Religion of the mother, Wealth index, Antenatal Visits of the mother, Hospital delivery of the mother, and Post-natal Check.

About $49 \%$ of the mothers in the study sample had a form of formal education, while the average age of the mother in the sample was 35years old. It was observed that in mother's religion, about $40.9 \%$ were Christians and about $57.7 \%$ Islam. The Wealth Index variable had $46.8 \%$ of the sample population fell within the poor quintile, $20.6 \%$ were in the middle quintile, while $32.5 \%$ of the sample fell within the rich quintile. $48.8 \%$ of the mothers went for at least four Antenatal visits and more, $32.4 \%$ of the women had hospital delivery, while $25.3 \%$ of the women went for postnatal checks from the sample.

The variables testing for the cultural aspect of the study were Age at first birth with a data ranging from ages 12 to 45 . The percentage of the under-aged mothers between the ages of $12-17$ (group 1) were $46.8 \%$ of the study sample. $46.7 \%$ were within the age group of $18-25$ years old, $6.2 \%$ of the mothers were in the $26-35$ age group, while $0.11 \%$ of the women were from ages 36-45. Almost half of the samples i.e., $46.8 \%$ of the mothers fell within the age of under-aged mothers or child marriage/ birth (12-17), this call for concern. The second variable is Partner's Education variable with 57\% of the partners having some form of formal education in the sample.

The environmental variables have Place of residence variable with $32.4 \%$ of the women in the sample living in an urban area while $67.5 \%$ living in the rural areas. The distance to the nearest health care center variable indicated that the sample has $32 \%$ of the women having a big problem in getting to the nearest healthcare facility. Mothers with piped water variable have $9.7 \%$ of the woman in the sample and lastly, the flush toilet variable has $9 \%$ of the women in the sample.

\section{PResentation of Results And Discussion}

\section{A. The Hotspots for Under-five Mortality Rate Result in Nigeria}

The spatial distribution of the U5MR as shown in Fig. 1. map, has six states with the highest U5MR marked in Red color. This ranged from 162-221 deaths per 1000 live births. 
The State of Zamfara had the highest U5MR with an estimate of 221 deaths per 1000 live births, followed by the State of Bauchi which had an U5MR of 210 deaths per1000 live births, Jigawa state with 200 U5MR/1000 live births, Sokoto with 185 U5MR/1000 live births, Kebbi state with 183 U5MR/1000 live births, and Katsina state with 183 U5MR/1000 live births.

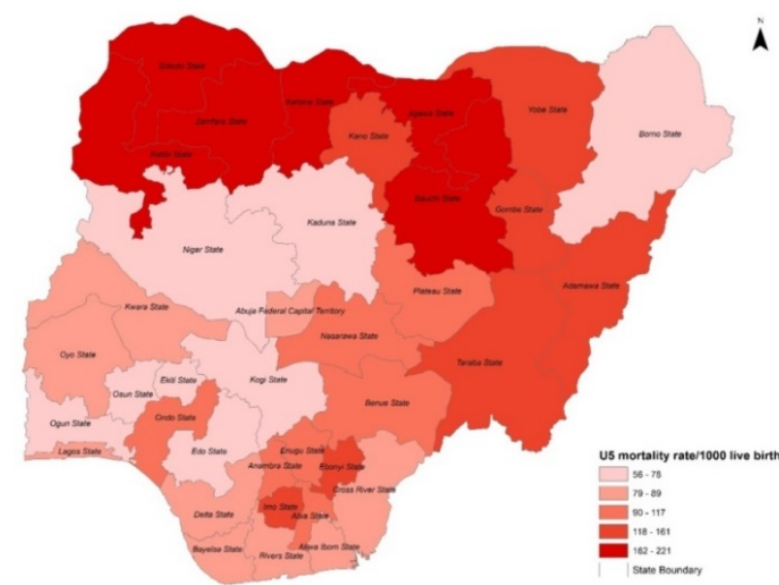

Fig 1. Distribution of under-five mortality rates across Nigerian states.

\section{B. Spatial Autocorrelation (Moran's I)}

The map also suggested a cluster pattern of under-five mortality rates between one state and the neighboring state, indicating possible autocorrelation presence. The Moran's I test used to check for the presence of auto correlation confirmed this, with an index of 0.4689 and a P-value of 0.01 . The results indicate that there is less than $1 \%$ likelihood that this clustered pattern could be a result of random chance. There is therefore a strong spatial dependence across Nigeria because the spatial pattern is clustered. Therefore, the null hypothesis is rejected and we accept the alternative hypothesis which states that there is spatial dependence across the study area (clustered). This therefore led to further analysis of checking for possible associations of cultural, maternal and environmental variables that could possibly be contributing to this high U5MR and clustering in these regions.

\section{Econometric Regression Results}

Below are the regression results of the analysis for determining variables contributing to the high under-five mortality in Nigeria as a whole and in the six states identified as the hotspots in the country using the two-stage least square probit model and the Gini coefficient.

\section{1) The country Nigeria as a whole}

The regression result for the country as a whole revealed a negative coefficients on maternal education and was statistically significant in the 2SLS at one $\%$ level $(\beta=$ $0.5977 ; P<0.01)$. The coefficient on Christianity was positive and statistically significant at the one $\%$ level level $(\beta=$ $0.2628 ; p<0.01$ ). Wealth index variable (rich) had a negative significant coefficient at less than five $\%$ level $(\beta=-0.2521$; $\mathrm{P}<0.05)$. Antenatal visits, hospital delivery and post natal care variables were positive and significant at one $\%$ levels $(\beta$ $=0.0523$, and 0.1275 and $0.0525 ; \mathrm{P}<0.01$ ).
The category of ages $12-17$ in the variable of age at first birth had its coefficient significant at less than ten $\%$ $(\beta=0.1341 ; \mathrm{P}<0.10)$. The Partner's education variable coefficient had a negative sign and was significant at less than one $\%,(\beta=-0.2252 ; \mathrm{P}<0.01)$. Under the environmental variables, the negative coefficients of distance to the nearest health care facility and flush toilet were significant at less than one \% levels $(\beta-0.0265$ and $-0.1989 ; \quad \mathrm{P}<0.01$ respectively). Finally, the piped water variable had a negative coefficient significant at one $\%$ level $(\beta=-0.0237 ; \mathrm{P}<0.01)$.

The maternal education increased, while the probability of under-five mortality decreased. Increasing the level of education by one will reduce the probability of under-five mortality by about $60 \%$. The partner's education was equally a significant variable, an indication that the education of fathers had an influence and increasing the father's level of education by one year would reduce the probability of underfive mortality in the country. Usually, educated fathers are most likely to marry educated mothers and vice versa.

The practice of delivering babies at the church or its environs is common in Nigeria, which could be the possible reason for the significance of the coefficient of Christianity variable. A times, complications which can only be handled by trained medical professionals are experienced and this could lead to the mortality of the child or mother thereby contributing to the high under-five mortality in the country. Such cases have contributed about 26.2\% under-five mortality to the national percentage.

$51.2 \%$ of the women in the country went for less than four or no antenatal visits. Therefore about $5.2 \%$ of the country's under-five mortality was as a result of the no or low antenatal visits. It is alarming that only $32.4 \%$ of the women had their babies delivered at the hospital through the help of a skilled worker, in other words, $67.6 \%$ of the women in the country had their babies delivered outside the hospital with not necessarily a skilled worker. This had contributed to the high under-five mortality in the country. Similarly, the significance of the post-natal variable contributing to the under-five mortality is likely as a result of just $25.2 \%$ of the women in the country went for post-natal check-ups. an indication that $74.8 \%$ of the women in the country did not go for post-natal checks, and this has contributed to the underfive mortality in the country by $5.2 \%$. The coefficient on variable wealth index was also significant with an inverse relationship implying that if wealth index increased by one unit, the probability of under-five mortality will decrease by 0.2521 or by $25.2 \%$ in the country.

The category of mothers within the ages 12-17years under the variable of age at first birth had its coefficient significant, an indication that if the country stops the pregnancy and birth of an under-age child by one, there is a probability of $13.4 \%$ reduction of under-five mortality. This is consistent with the findings from Finlay et al. [26], which emphasized teen pregnancy as a risk factor with a result showing $23.9 \%$ of infant mortality with women between the ages of 15 and 17 at their first birth and $35.2 \%$ with women between the ages of 18 and 20 . Children born to women aged 12-14 or 15-17 were significantly more likely to die in their first year of life than children born to women aged 27-29.

Under the environmental variables, the distance to the nearest health care facility and the flush toilet variables were 
significant Improving on the distance to the nearest health care facility by one kilometer, will reduce the probability of under-five mortality by 2.65 , while for the flush toilet variable, it can be seen that it contributed $19.9 \%$ to the national under-five mortality. This is possibly because just $9.1 \%$ of the women under investigation have flush toilets, thereby making $90.9 \%$ of the women without flush toilets, (from the descriptive statistics done). Finally, the piped water variable was also significant, and also an indication that if an additional one unit of the piped water is consumed, there would be a possibility of a reduction in the probability of under-five mortality by $2.37 \%$. The Gini coefficient for the country as a whole was 0.5468 . Compare with other African countries with low index such as Algeria with a Gini coefficient of 27.6, Nigeria still has a high level of income inequality among her citizens. When a country has a high percentage of income inequality, it could lead to higher degrees of health and societal glitches, lower proportions of social goods, a lesser population-wide satisfaction and contentment, lesser level of economic growth and development, amongst other problems.

A separate regression analysis was performed for each of the six states, below are the results for Sokoto, Zamfara, Katsina, Bauchi, Jigawa and Kebbi states.

\section{2) State 1: Sokoto}

The regression results for Sokoto State showed the coefficient on maternal education was statistically significant at one percent level $(\beta=-0.0384, p<0.01)$ in the 2SLS model. $(\beta=\mathrm{xxx}, p<\mathrm{xx})$. Similarly, the coefficient for the partner's education variable was also significant although with a low level of significance of ten $\%$ as compared to the mother's education $(\beta=-0.0438, p<0.10)$.

The coefficient of the maternal age variable was highly significant at one $\%$ level $((\beta=0.0041, p<0.01)$ in the 2 SLS analysis, while the wealth index coefficients for the middle and rich category was significant at less than one and five $\%$ levels of significance $(\beta=-0.0643$ and $-0.1257 ; p<0.01$ and, $p<0.05$, respectively). The coefficient of the sanitation variable (Flush) was significant at five $\%$ level $(\beta=-0.4276$; $p<0.05)$. The overall model fits reasonably well because it is correctly classified at $84.33 \%$.

Sokoto state is located in the northwestern part of Nigeria and the positive sign on the coefficient on maternal education implied that maternal education was a contributing factor to the high under-five mortality in Sokoto state. This is against a priori knowledge; however, it could imply that the high percentage of $16.2 \%$ of mothers with non-formal education contributed to the high under-five mortality in the state This further implied that the higher the level of education, the lower the under-five mortality. Also, the more mothers that were educated, the less under-five mortality will be. Furthermore, education should have a positive influence on reducing and not increasing under-five mortality. Similarly, the coefficient on partner's education variable was also significant, although with a lower level of significance as compared to the mother's education, implying that, the level of education of the father played a role in reducing under-five mortality in Sokoto state by $4.3 \%$. The positive sign on the age of the mother is as expected. This implies that generally at a certain point, the older a woman gets the higher the chances of her losing a child because of her biological and physiological composition, especially during childbirth. This variable is also a contributor to the high under-five mortality in Sokoto state.

The negative sign on the variable coefficients is an indication that if wealth index and flush are increased by one unit, the probability of under-five mortality will reduce by 6.4 (middle), 12.5 (rich) and 42.7\%, respectively. This attests to the state of urbanization in the state of Sokoto and environmental factors likely contributing to the high underfive mortality. Sokoto is located in one of the poorest geopolitical zones in Nigeria. And according to the National Bureau of Statistics (NBS) report [27], Sokoto State has retained its position as the poorest state in the country, with $81.2 \%$ poverty rate. This implies that the high poverty level of the state will influences some basic amenities necessary for its citizens and their places of residence, which will mostly be a poor state of living. The Lorenz curve and the inequality index for Sokoto state is far away from the equality line implying an unequal distribution of income with more income being held by the rich in the society. The gini coefficient was 0.7962 , an implication of $79.6 \%$ income inequality in Sokoto state. This in turn could have had an impact and contributed to the high under-five mortality rate in the state.

\section{3) State 2: Zamfara State}

The regression result for Zamfara State had the coefficient of maternal age significant at less than one percent $(\beta=$ 0.0044; $p<0.01$ ) for the 2 SLS analysis. The partner/father's education variable coefficient was significant at less than five percent level of significance $(\beta=-0.0641 ; p<0.05)$.

The variable Age at first birth had the coefficient of the ages $12-17$ category (under-age) significant at less than five $\%$ level of significance $(\beta=0.1150 ; p<0.05)$. The coefficients on the wealth index variable (middle and rich) $(\beta=-0.0868$ and $\beta=-0.2753$ ) were statistically significant at five and ten $\%$ levels respectively ( $p<0.05$ and $p<0.10$ ), although at a low level of significance for the middle and rich class.

The negative coefficient of the distance to the health care facility was another significant variable at one $\%$ level of significance $(\beta=-0.0503 ; p<0.01)$. The overall model is correctly classified at $84.93 \%$.

Zamfara State had the highest number of under-five mortality rate in Nigeria with a rate of 221 deaths per 1000 live births. The positive sign on the coefficient of the maternal age is an indication that maternal age is a contributing factor to the under-five mortality. This could a possible situation of under-aged mothers or over-aged mothers in the state. However, this was affirmed by the variable Age at first birth which had the coefficient of the ages 12-17 category (underage) significant. Sadly, this could be a possible implication of the practice of child marriage in the state. Zamfara state was the first state to officially adopt the Sharia legal system in 2002, and child marriage is endemic in the state [28] just like most Northern States in Nigeria. This practice being a ripple effect, will equally affect negatively the education of these children brides, thereby also contributing to the high underfive mortality rate in the state, however, the partner's education variable helped to reduce under-five mortality in Zamfara state by $6.4 \%$. 
The negative coefficients on the middle and rich class of the wealth index variable were an indication of an inverse relationship between wealth and under-five mortality. In other words, the wealthier a person or household is, the lesser the under-five mortality. However, looking at the socioeconomic status of Zamfara state, according to the National Bureau of Statistics record in 2017, Zamfara was the poorest state in Nigeria with $91.9 \%$ ( $\mathrm{H}$ incidence $\mathrm{K}=33.3 \%$ ) and MPI $=0.605$ and $65.8 \%$ A-intensity. Although Sokoto State was said to be the poorest state in Nigeria as at the year 2019, however, Zamfara State also fell among the 10 poorest States in the country with $70.8 \%$ poverty rate. This was confirmed by our Gini coefficient calculation of 0.8887 on, implying an $88.8 \%$ income inequality in Zanfara state. Poverty affects living standards, which in turn could contribute to under-five mortality in the state.

Another variable of interest was the distance to the nearest health care facility. The negative coefficient was an indication of an inverse relationship between the distance to the nearest the health care facility and the under-five mortality. A study carried out in Zamfara state by Maiwada et.al. [29], showed that maternal and child mortality rates were high in the state because of factors such as underutilization of health care facilities which may be as a result of the bad and poor attitude of some health care service providers and the way the women were treated may have compounded the situation of underutilization of the health care by the women, who also may have to travel hours and long distances coupled with long waiting hours at the health facility for them to receive care may have contributed to the bad situation of health care service utilization and delivery in Zamfara state.

\section{4) State 3: Katsina State}

The 2SLS analysis done on Katsina state had the coefficient 0.0059 of maternal age significant at less than one $\%$ level of significance $(\beta=0.0059 ; p<0.01)$. The coefficients on the variable age at first birth were significant at five and one $\%$ levels of significance $(p<0.05$ and $p<0.01)$ for the categories of the ages 12-17 (under-age) and ages 3645respectvely $(\beta=0.1453$ and $\beta=0.5531$ respectively). The overall model is correctly classified at $84.58 \%$.

In Katsina state the maternal age variable was also significant. The same explanation as in other states above also applies for Katsina as there may be a presence of under-age or over age mothers in the state contributing to the high under-five mortality, with the variable being significant and positive. This was also further affirmed by the coefficient of age at first birth being significant. This implies that $14.5 \%$ of under-five mortality was contributed by under-aged mothers, while $55.3 \%$ of the under-five mortality was contributed by over-aged mothers. This also affirms the significance of the maternal age coefficient above. Furthermore, the significance of the variables could also imply that Katsina State also has some significant form of child marriage practice, which is likely influenced by cultural and religious believes. Therefore, just like the states analyzed above, Katsina state also has all the negative effects that comes with under-aged marriages and births including under-five mortalities equally applying in the state.
Katsina had a poverty rate of $74.5 \%$ in 2014 which increased to $82.2 \%$ in 2017 (NBS) [30]. Katsina state fell among the 10 poorest states in Nigeria, a state located at the deepest part of the north western area of Nigeria, with fewer or no solid investment or sector that generates revenue for the state. The Gini coefficient from the inequality analysis was 0.7811, while the Lorenz curve was equally far away from the equality line, signifying a large range of income inequality in the state. Therefore, just like the states mentioned above, poverty, affects living standards, which in turn could contribute to the high under-five mortality rate of 183 deaths per 1000 live births in the state.

\section{5) State 4: Jigawa}

Jigawa State is situated in the north-western part of the country, and for Jigawa state we had data limitation challenge, however, the 2SLS done had the coefficient on maternal age significant at less than one $\%$ level of significance $(\beta=0.0072 ; p<0.01)$. The category of ages 12 17 in the variable age at first birth had its coefficient significant at five $\%$ level of significance $(\beta=0.1063 ; p$ $<0.05)$.

The categories of middle $(\beta=-0.0734 ; \mathrm{P}<0.05)$ and rich $(\beta$ $=-0.1945 ; p<0.01)$ for the wealth index variable were significant at less than five and one $\%$ levels of significance. The distance to the nearest health care center also had a significant coefficient at less than one $\%$ significance level $(\beta$ $=-0.0477 ; p<0.01)$. The overall model is correctly classified at $84.54 \%$.

Maternal age was equally confirmed by the category of ages 12-17 years in the variable age at first birth having a significant coefficient. Also, the results still indicated that just like the other northern states examined above, child marriage is practiced or under-aged giving birth can be found in this state and it is wide spread. Therefore, this cultural and religious practice brings about all the negative side effects of children brides and underage marriages in Jigawa State, one of which is the high under-five mortality in the state.

The negative coefficient on wealth index for Jigawa state, being an inverse relationship between wealth index and under-five mortality was consistent with some of the other northern states earlier discussed. An increase in wealth index, will bring about the probability of a decrease in under-five mortality. The distance to the nearest health care center also had an inverse relationship, implying that if the distance to the nearest health center is improved by one kilometer, there will be a probability of $4.7 \%$ decrease in the under-five mortality. The significance of the wealth index and distance to the nearest health care center could be an indication of a likely poor standard of living, It could be an indication of inadequate environmental and basic amenities, such as good roads or hospitals. According to Bichi [31] and the study conducted in Kazaure, Jigawa, the healthcare facilities were categorized into primary, secondary, and tertiary, whereby primary was having $78.95 \%$, secondary $21.05 \%$, and tertiary $0 \%$. Another study carried out by Musa Jaro \& Adamu Ibrahim [32], examined and explained how accessibility problems affected the level of utilization of the primary health care system (as measured by the location hospitals) in Jigawa state. The result revealed that distribution of primary health care centers and facilities were not homogeneous because of 
political policy and so their locations did not offer equal accesses or uniform benefits to the rural people. It was also found out that few settlements had primary health centers and cottage hospitals located in them and they were poorly connected by road. And so, the number of people utilizing the primary health care centers and facilities declined because of the increasing distance between their places of residences and points where they obtained health services. These had contributed to the high under-five mortality rate of 200 deaths per 1000 live births in the state in the year 2013 from the data.

Jigawa State is also one of the 10 poorest states in Nigeria with a poverty rate of $74.1 \%$ in 2014 and increased to of $88.4 \%$ in 2017 but dropped a bit in the year 2019 to $72.1 \%$ [30], this is as a result of low literacy level and low economic growth in the state. From the inequality analysis, the Gini coefficient for Jigawa State was 0.8850 , implying $88.5 \%$ income inequality in the state, and the Lorenz curve was far away from the equality line signifying a wide income inequality distribution in the state.

\section{6) State 5: Bauchi State}

Bauchi state is located in the north eastern part of Nigeria. There was only one significant coefficient of a variable under the 2SLS analysis which was the category of ages $12-17$ years (under-aged mothers) under the variable age at first birth, which was significant at less than five $\%$ level of significance $(\beta=0.1063 ; p<0.05)$. The overall model is correctly classified at $84.97 \%$.

The analysis revealed that about $10.6 \%$ of the under-five mortality was as a result of under aged mothers. According to a report on the status of women's rights in Nigeria presented by Women Advocacy Research and Documentation Centre (WARDC) [33], Bauchi state was one of the states having the highest number of child marriages of $84 \%$ in Nigeria. Citing United Nations statistics, the organization also announced that girls under 17years were responsible for 7.3 million babies in developing countries. Bauchi is a war-torn zone and Statistics from the National Bureau of Statistics showed that bulk of the populaces in this area do not have the basic amenities of life. The death rate recorded after the various rebellious attacks were devastating. No doubt, this situation had contributed to the high under-five mortality rate in the state, coupled with the negative effects of these children's marriages on their education, health and life as a whole as mentioned earlier above.

In 2014 according to a report by The Oxford Poverty and Human Development Initiative (OPHI) [34], it was revealed that Bauchi State had the highest percentage of people living in extreme poverty, followed by Kebbi State. According to the recent NBS 2019 report, Bauchi ranked among the 10 poorest states in Nigeria with $86.6 \%$ poverty rate. Also, from the inequality analysis done, the Gini coefficient for Bauchi state was 0.8121 , and the Lorenz curve is far away from the equality line, an implication of a wide income inequality. This was also a contributing factor to the high under-five mortality rate of 210 deaths per 1000 live births in Bauchi state.

\section{7) State 6: Kebbi State}

The results from the 2SLS for Kebbi State showed that the coefficients on the maternal education and partner's education variables were significant at less than one $\%$ level of significance $(\beta=0.7092$ and $-0.2658 ; p<0.01)$. Two categories under the age at first birth variable: underage mothers, i.e., ages 12-17years and 18-25 years, were significant at less than one $\%$ level of significance $(\beta=0.2083$ and $\beta=0.1588 ; p<0.01)$.

The maternal education variable had a positive sign on its coefficient which is contrary to a prior expectation, because maternal education should lower under-five mortality, however, this could be a possible indication of a low level of formal education for the mothers in this state, or probably girls enrolment in schools are low. On the other hand, the negative sign on the coefficient of fathers/partner's education variable is an indication that the educational level of the father has an inverse relationship with under-five mortality, thereby bringing a reduction to the level of under-five mortality. If the level of partner's education is increased by one, there is a probability that under-five mortality will reduce by $26.6 \%$ in Kebbi state. In a situation where the mother's education is a contributing factor to the under-five mortality in the state and the opposite is the situation for the father's education, it signifies that the efforts on maternal education or girl's enrolment is low in Kebbi state. There is an indication of possible practice of child marriages or underage girls having babies with a significant coefficient on age at first birth variable. This just like the other states discussed above could lead to many issues, one of which is high underfive mortality in the state.

The antenatal visits variable had a negative coefficient which was significant at less than one $\%$ level of significance $(\beta=-0.1133 ; p<0.01)$, while the post-natal check had a significant negative coefficient at five $\%$ level of significance $(\beta=-0.2839 ; p<0.05)$. The wealth index (rich) variable was also significant at one $\%$ level of significance with a negative coefficient $(\beta=-0.2896 ; \mathrm{P}<0.01)$. The antenatal visits and the post-natal check variables were both contributing factors to the under-five mortality; however, if the antenatal visits or post-natal checks were increase by one, there is a probability of under-five mortality reduction by 11.3 and $28.3 \%$, respectively, of which Kebbi State has a mortality rate of 183 deaths per 1000 live births.

The wealth index (rich) variable was also significant $(\mathrm{P}<0.01)$ with a negative coefficient of -0.2896 , an indication of an inverse relationship between wealth index and underfive mortality. Therefore, if wealth index is increased by one unit, there is a probability of $28.9 \%$ decrease in under-five mortality. According to the report by The Oxford Poverty and Human Development Initiative (OPHI) [34], it was revealed that Kebbi State had the second highest percentage of people living in extreme poverty in Nigeria. A recent report by Oxford Poverty and Human Development Initiative revealed that Kebbi State had a poverty rate of $86.0 \%$. From the analysis on inequality on the state, the Gini-coefficient was 0.8261 , while the Lorenz curve was far away from the line of equality. The urban areas in Kebbi State accounted for only about $12.5 \%$ of the population of the state. Thus, more than eighty $\%$ of the population lives in the rural areas with limited resources and amenities. These could also be contributing factors to the high under-five mortality in the State. The overall model is correctly classified at $84.53 \%$. 


\section{Summary AND CONClusion}

\section{A. Summary}

In summary, the results have shown that age of the mother, and age at first birth were significant predictors of under-five mortality rate. The plausible explanation for this could be early child marriage common in most of the states in Northern Nigeria. To address the issue of early marriages, the government has put in place laws for example the Child Rights Act. However, this Act has not been effective because it is optional for states and child marriage can be practiced within the states that have not enacted the law locally.

Another significant variable that was relatively consistent in the hotspot states was the distance to the nearest health care center. Accessibility to the nearest health care center is also a major challenge in these States (especially in the rural areas) because of the distance to the health facilities and poor road connections. When there is a problem with accessibility to a health center, the level of utilization of such centers can be a problem. Also because of the unequal distribution of medical centers around these states, accessibility and utilization becomes more challenging. If the structures and amenities are improved upon, the standard of living in these rural places will also improve, as a result the probability of under-five mortality will also be reduced. In other words, the more an area is urbanized the less the under-five mortality.

\section{B. Conclusion}

The clustering pattern observed after the mapping of the under-five mortality led to the testing of the spatial autocorrelation, using the Moran's I. the result revealed that there was a positive spatial autocorrelation. It was observed that the red zone, which had a cluster of states with the highest number of under-five mortality in the country were located in the northern part, precisely the north-east and north-western part of Nigeria. This led to checking for variables that could be contributing to the clustering pattern observed in the regions, thereby checking some maternal environmental and cultural variables for associations with the under-five mortality rate, to see if these variables can explain the high under-five mortality rates and the spatial clustering pattern. From the results, we observed that the coefficient of the variable Age of the mother and, Age at first birth were relatively significant across the six states under examination. We observed that the states were part of the poorest states in the country, with high poverty rates. Poverty affects the living standards of people and dictates their life choices, such as places of residence, types of healthcare insurances, etc. This could be one of the reasons for the clustering pattern observed and the high under-five mortality rates. We also observed that Islam is the main religion in these states and all the states under analysis had adopted the Sharia law and all its guiding principles as their operational law. It was also observed that the cultural and religious practices in these states support children marriages, i.e. marriages of children less than 18 years of age. Statistics of child marriage in Nigeria in the year 2017 was $43 \%$ of girls married off before the age of $18,17 \%$ were married before they turned 15 (Child marriage around the world: NIGERIA", Girls Not Brides). (African Commission on Human and People's Rights, Protocol to the African Charter on Human and Peoples' Rights on the Rights of Women in Africa, [website], 2018) [35]. Nigeria is at the $11^{\text {th }}$ position among nations with the highest number of child marriages globally (New York Times, Child, Bride, Mother: Nigeria, [website], 2017) [36]. Meanwhile, the regions with the highest percentage in Nigeria are the North West and North Eastern regions with $68 \%$ and $57 \%$ of child marriages respectively. The negative effects of this practice can be seen across the six states, because the children marriages led to the low level of education especially for the girl child, health issues that came with children having children, which eventually led to complications, a high mortality rate of under-five children and even their mothers.

In conclusion therefore, awareness through the media and all available means need to be intensified on the practice of child marriages, while emphasis needs to be laid on effective programs, policies and amendments of laws (especially the laws that affects children marriages: Part 1 Section 61 of the 1999 Constitution of the Federal Republic of Nigeria should be amended, and the Child Rights Act (2003) should be automatically enacted in all states, while unvarying age should be set for a child to marry in order to protect the rights of children in the country) in the north-east and north-western part of Nigeria by the government and other relevant associations or institutions, to help eradicate/reduce the under-five mortality rate and to help break this clustering pattern observed in the regions. Programs that will help alleviate poverty in these regions should be of uttermost priority for the governance as this will go a long way to stabilize the families financially, improve living standards, provide better health care, eradicate/ reduce child marriages/under-aged mothers who eventually will reduce under-five mortality in these regions.

\section{REFERENCES}

[1] Musa, G. J., \& Chiang, P. (2013) Use of GIS Mapping as a Public Health Tool-From Cholera to Cancer. Health Services Insights, 6:111-6. DOI: 10.4137/HSI.S10471.

[2] Tobler W., (1970) "A computer movie simulating urban growth in the Detroit region". Economic Geography, 46(Supplement): 234-240.

[3] United Nations Children's Fund Data, 2019.

[4] Tanja AJ Houweling, Anton E Kunst, Caspar WN Looman, Johan P Mackenbach, Determinants of under-5 mortality among the poor and the rich: a cross-national analysis of 43 developing countries, International Journal of Epidemiology, Vol. 34, Issue 6, December 2005, Pages 1257-1265, https://doi.org/10.1093/ije/dyi190.

[5] Alabi, O., Oyedokun, O., Doctor, H., \& Adedini, S. (2015). Determinants of under-five mortality clustering in a health and demographic surveillance in Zamfara State, northern Nigeria. African Population Studies.

[6] Salau, S., Galpin, J., \& Odimegwu, C. (2007). Spatial pattern of child mortality in Nigeria. Presented at the Population Association of America, 2006 Annual Meeting, Los Angeles, CA.

[7] Klouda, A. T. \& Adamu, F. (2013). Clustering of Child Mortality and Links to Social Support in Northern Nigeria. A report submitted to PRRINN-MNCH Programme. Available from www.prrinnmnch.orgaccessed last on June 15, 2015.

[8] Vandezande M, Moreels S, Matthijs K. Explaining death clustering: Intergenera-tional patterns in infant mortality Antwerp 1846-1905, Working paper of the Scientific Research Community Historical Demography, Centre for Sociological Research, Leuven; 2010. Available:https://lirias.kuleuv.

[9] Burke, M., Heft-Neal, S., \& Bendavid, E. (2016). Sources of variation in under-5 mortality across sub-Saharan Africa: a spatial analysis. Lancet Glob Health; 4: e936-45.

[10] Salau, Sulaiman (2013) Spatial Variations in Under-Five Mortality in South Africa. University of the Witwatersrand, Johannesburg, South Africa. Proceedings $59^{\text {th }}$ ISI World Statistics Congress, 25-30 August 2013, Hong Kong (Session CPS203). 
[11] Uthman O. (2007). Environmental Factors, Neighbourhood Deprivation, And Under-Five Mortality in Nigeria: An Exploratory Spatial Data Analysis. The Internet Journal of Pediatrics and Neonatology. 2007 Vol. 9, Number 1.

12] Quattrochi, J., Jasseh, M., Mackenzie, G., \& Castro, M. (2015). Spatial analysis of under- 5 mortality and potential risk factors in the Basse Health and Demographic Surveillance System, the Gambia. https://doi.org/10.1111/tmi.12490.

[13] Woldeamanuel. B. T. (2019). Socioeconomic, Demographic, and Environmental Determinants of Under-5 Mortality in Ethiopia: Evidence from Ethiopian Demographic and Health Survey, 2016. Child Development Research, vol. 2019, Article ID 1073782, 15 pages, 2019. https://doi.org/10.1155/2019/1073782.

[14] Singh and Tripathi Springer Plus 2013. Retrieved from, http://www.springerplus.com/content/2/1/284

[15] Mesike, C. G. \& Mojekwu, J. N. (2012). Environmental Determinants of Child Mortality in Nigeria. Journal of Sustainable Development, Vol. 5, No. 1; January 2012. doi:10.5539/jsd.v5n1p65 URL:http://dx.doi.org/10.5539/jsd.v5n1p65.

[16] Alaba, O.O., Olubusoye, O. E., Korter G. O., (2014). Spatial Dependencies in Under Five MortalityRates in Nigeria using Proximate Environmentaland Maternal Determinants. Journal of the Nigerian Statistical Association, Vol. 26, 2014, 127-143.

[17] Mosley, W.H., Chen, L.C. (1984): An analytic framework for the study of child survival in developing countries. Population and Development Review, 1984, 10:25-45.

[18] Rosenzweig, M. R., \& Schultz, T. P. (1983). Estimating a Household Production Function: Heterogeneity, the Demand for Health Inputs and Their Effects on Birth Weight. Center Discussion Paper, No. 437, Yale University, Economic Growth Center, New Haven, CT.

[19] Moran, P.A.P. (1948). The interpretation of Statistical Maps. Journal of the Royal Statistical Society: Series B (Methodological). https://doi.org/10.1111/j.2517-6161.1948.tb00012.x.

[20] Mwabu G. (2009). The Production of Child Health in Kenya: A Structural Model of Birth Weight, Journal of African Economies, Vol. 18, Issue 2, Pages 212-260, https://doi.org/10.1093/jae/ejn013.

[21] Mwabu, G. (2008). The Production of Child Health in Kenya: A Structural Model of Birth Weight. Yale University Economic Growth Center Discussion Paper No. 963; Yale Economics Department Working Paper No. 52. Available at SSRN: https://ssrn.com/abstract=1272468.

[22] Somanathan, A. (2008). Use of Modern Medical Care for Pregnancy and Childbirth Care: Does Female Schooling Matter? Policy Research Working Paper 4625. The World Bank East Asia and Pacific Region, Human Development Sector Department Health, Nutrition and Population May.

[23] Andriano, L., Monden, C.W.S. (2019). The Causal Effect of Maternal Education on Child Mortality: Evidence from a Quasi-Experiment in Malawi and Uganda. Demography, 56, 1765-1790 (2019). https://doi.org/10.1007/s13524-019-00812-3.

[24] Maiga, E. (2015). Mother's Education and Children's Nutrition Outcomes in Burkina Faso: Is there a Strong Causal Relationship? AGRODEP Working Paper 0019. Washington, DC: International Food Policy Research Institute. http://ebrary.ifpri.org/cdm/ref/collection/p15738coll2/130102.

[25] Nigeria Demographic and Health Survey Data 2013.

[26] Finlay, J. E., Özaltin E., \& Canning D. (2011). The association of maternal age with infant mortality, child anthropometric failure, diarrhea and anemia for first births: evidence from 55 low- and middleincome countries, BMJ Open 2011;1:e000226. doi: 10.1136/bmjopen2011-000226.

[27] Nigeria Demographic Health Survey (NDHS) reports: National Bureau of Statistics, Nigeria (2013). https://nigeria.opendataforafrica.org/data\#source=NBS-NG.

[28] Iyabode, O. (2011). Child Bride and Child Sex: Combating Child Marriages in Nigeria. Nnamdi Azikiwe University Journal of International Law and Jurisprudence: Vol 2.

29] Maiwada, A. M., Rahman, N. A., Rahman, S. A., Mamat, N. M., \& ABaba. T. (2015). The Health MDGs in Zamfara State with emphasis on Maternal Mortality 2010-2015: Perspectives and Challenges. Journal of Development Administration, Vol. 2, No.1.

[30] National Bureau of Statistics Data (2017 \& 2019).

[31] Bichi, T. M. (2014). Analysis of the Spatial Distribution of Health Care Facilities in Kazaure Local Government, Jigawa State, Nigeria (Draft). Department of Urban and Regional Planning Hussaini Adamu Federal Polytechnic.

[32] Musa Jaro \& Adamu Ibrahim (2019). The accessibility problems of primary health care to rural people in Jigawa State, Nigeria. Research Gate.
[33] Women Advocacy Research and Documentation Centre (WARDC) (2017).

[34] The Oxford Poverty and Human Development Initiative (OPHI), 2014.

[35] African Commission on Human and People's Rights, Protocol to the African Charter on Human and Peoples' Rights on the Rights of Women in Africa 2018. https://www.achpr.org/resources.

[36] Child, Bride, Mother: Nigeria, 2017 report. Retrieved from https://www.girlsnotbrides.org/child-marriage/nigeria/. 